\title{
Genome-Wide Identification and Expression Analysis of $M A P K$ and MAPKK Gene Family in Pomegranate (Punica Granatum L.)
}

\author{
Yuan Ren ${ }^{1,2}$, Dapeng Ge ${ }^{1,2}$, Jianmei Dong ${ }^{1,2}$, Linhui Guo ${ }^{1,2}$ and Zhaohe Yuan ${ }^{1,2, *}$ \\ 1 Co-Innovation Center for Sustainable Forestry in Southern China, Nanjing Forestry University, \\ Nanjing 210037, China; renyuan426@njfu.edu.cn (Y.R.); gedapeng@njfu.edu.cn (D.G.); \\ djm@njfu.edu.cn (J.D.); glhnl@njfu.edu.cn (L.G.) \\ 2 College of Forestry, Nanjing Forestry University, Nanjing 210037, China \\ * Correspondence: zhyuan88@hotmail.com
}

Received: 6 June 2020; Accepted: 13 July 2020; Published: 14 July 2020

\begin{abstract}
Mitogen-activated protein kinase (MAPK) cascade is involved in the regulation of a series of biological processes in organisms, which are composed of MAPKKKs, MAPKKs, and MAPKs. Although genome-wide analyses of it has been well described in some species, little is known about MAPK and MAPKK genes in pomegranates. In this study, we identified 18 PgMAPKs, 9 PgMAPKKs through a genome-wide search. Chromosome localization showed that 27 genes are distributed on 7 chromosomes with different densities. Multiple sequence alignment and phylogenetic analysis revealed that $P g M A P K s$ and $P g M A P K K s$ could be divided into 4 subfamilies (groups $\mathrm{A}, \mathrm{B}, \mathrm{C}$, and D), respectively. In addition, exon-introns structural analysis of each candidate gene has indicated high levels of conservation within and between phylogenetic groups. Cis-acting element analysis predicted that $P g M A P K s$ and $P g M A P K K s$ were widely involved in the growth, development, stress and hormone response of pomegranate. Expression profile analyses of $P g M A P K s$ and $\operatorname{Pg} M A P K K s$ were performed in different tissues (root, leaf, flower and fruit), and PgMAPK13 was significantly expressed in all tissues. To our knowledge, this is the first genome-wide analysis of the $M A P K$ and $M A P K K$ gene family in pomegranate. This study provides valuable information for understanding the classification and functions of pomegranate MAPK signal.
\end{abstract}

Keywords: Punica granatum; gene family; MAPK; MAPKK; gene expression

\section{Introduction}

In the long process of evolution, plants have evolved complex signal network regulation mechanism to adapt to the biotic and abiotic stress during growth and development [1-4]. The mitogen-activated protein kinase (MAPK) cascade is regarded as one of the typical mechanisms of signal transduction. As broad and relatively conservative evolutionary pathway, it is involved in multiple metabolic pathways such as cell division, development process and defense response in organism [5-7]. The typical MAPK cascade is composed of three specific kinases, MAP kinase (MAPK), MAPK kinase (MAPKK), and MAPKK kinase (MAPKKK) [8]. They are activated by phosphorylation and dephosphorylation at specific sites [9]. According to sequence alignment and phylogenetic analysis of model species Arabidopsis thaliana [9], the MAPK and MAPKK genes can be divided into four groups (A, B, C, and D). MAPK family members all have a unique "TxY" phosphorylation motif, while the MAPKK genes are activated when serine and serine/threonine residues in the "S/TXXXXXS/T" motif [10]. Despite the highly conserved structure of plant $M A P K s$ and $M A P K K s$, they have been shown to be extensively involved in plant growth, and hormonal response regulation processes, as well as diverse biological and abiotic stress $[11,12]$. To date, members of the MAPK cascade gene family have been identified in 
several species such as Arabidopsis thaliana [13,14], Oryza sativa [15,16], Brachypdoium distachyon [17], Zea mays [18], and Hordeum vulgare [19].

Numerous studies have shown that the MAPK cascade pathway mekkl-mkk4/5-mpk3/6 is involved in the biosynthetic pathway of phytoalexins [20]. In response to the pathogen, Arabidopsis thaliana induced the expression of related defense genes by activating two MAPK cascade pathways, mekkl-mkk1/2-MPK4 and mekk1-mkk4/5-mpk3/6, in which the former played a negative regulatory role [21,22], while the latter played a positive regulatory role [23]. In terms of signaling under abiotic stress, studies have shown that a variety of MAPKs, including MAPK3, MAPK4 and MAPK6, can be rapidly activated in plants under abiotic stress [23]. For example, the transcriptional level of ZmMPK3 in maize significantly increased and rapidly increased under multiple stresses such as cold, drought, ultraviolet, salinity, heavy metal, and mechanical damage [24,25]. Overexpression of OsMAPK5 in transgenic rice can increase its tolerance to drought, salt, and cold stress [26], and RaMPK1, combined with RaMPK2 were significantly up-regulated in response to low temperature stress [27]. In the field of plant hormone signaling, MAPKS and MAPKKs are involved in the signaling of auxin, abscisic acid, and ethylene. Activity of MAPKs has been found to be directly dependent on abscisic acid stimulation in different plants such as rice [15,16], corn [18], barley [19], and tobacco [20]. OsMAPK5 (OsMAP1), OsMAPK2, OsMAPK44 and other MAPKs can be activated by ABA transcription [28]. MPK3 and MPK6 in Arabidopsis play roles in the ethylene response pathway by promoting the stability of the key transcription regulator EIN3 [29]. It has been found that the mkk9-mpk3/MPK6 cascade controls EIN3 transcription to regulate ethylene signaling in plant cells and links the interwoven MAPK cascade pathways to control the quantitative response and specificity in the signaling network [30]. Since the research on the MAPK and MAPKK gene families has become increasingly intensive and comprehensive, we place emphasis on these two families in this paper.

Pomegranate (Punica granatum L.) is an economic tree widely cultivated throughout the world [31-34]. Native to central Asia, it is known for its bright red rinds, juicy kernels, and allagenic tannins [35,36]. With the advancement of molecular biology and bioinformatics methodology, it is of great significance to study the functions about signal transduction pathways in plants under stress response, cell growth and development, and comprehensive disease resistance [37]. A new high-quality genome sequence has been published, making it possible to study the gene family of pomegranates [38]. However, no information on pomegranate $M A P K$ and $M A P K K$ gene family at genome-wide level is currently available.

In this study, the MAPK and MAPKK gene family members of pomegranate were systematically identified at the genome-wide level using the pomegranate "Tunisia" genomes. Physicochemical properties, chromosomal locations, gene structures, cis-acting elements, and expression patterns of PgMAPKs and PgMAPKKs were carefully analyzed, which would be conducive to further research on the application in pomegranate growth and development.

\section{Materials and Methods}

\subsection{Genome Data Sources}

Pomegranate genome-wide data (SAMN05193489) were downloaded from NCBI's official website (https://www.ncbi.nlm.nih.gov/biosample/SAMN05193489/); The MAPK and MAPKK protein sequences of Arabidopsis thaliana were obtained from EnsemblPLants database (http://plants.ensembl. org/index.html) [39] (Fasta file S1, Table S1).

\subsection{Identification of PgMAPKs and PgMAPKKs in Pomegranate}

The protein kinase domain sequence comparison file (Pfam accession No.PF00069) was downloaded from Pfam database (http://pfam.xfam.org/) [40]. HMMER v3.2.1 software [41] was used to convert the comparison file into HMM model file. Selecthmm package (https: //github.com/Redpome/SelectHMM) (E-value 10-10 or less) was used to get pomegranate protein 
sequence containing MAPK cascade genes sequence structure domain. Moreover, the protein domains were validated by online program SMART (http://smart.embl-heidelbergDE) [42] and NCBI CDD (https://www.ncbi.nlm.nih.gov/CDD) [43]. The isoelectric points and molecular weights of PgMAPKs and PgMAPKKs were obtained by the ExPASy Proteomics Server (http://expasy.org/) [44].

\subsection{Phylogenetic Relationship and Conserved Motif Analysis}

ClustalX V2.0 [45] was used for multi-sequence alignment of identified proteins of PgMAPKs and PgMAPKKs (Fasta file S2) with parameters set as default values. The results were then submitted to GeneDoc [46] for visualization. A neighbor-joining phylogenetic tree was constructed with MEGA V7.0 [47] (selecting position model with 1000 bootstrap replicates) to explore the phylogenetic relationships of $P g M A P K$ and $P g M A P K K$ family members based on the full-length protein sequence. The conservative motif was obtained by online program MEME (http://meme.nbcr.net/meme/intro. $\mathrm{html}$ [ [48] based on the expectation maximum (EM) algorithm. The introns and exons of PgMAPKs and PgMAPKKs genes were analyzed and visualized by TBtools V0.6696 [49]. Finally, the 2.0kb upstream DNA sequence of each candidate gene was extracted, and then submitted to Plantcare database (http://bioinformatics.psb.ugent.be/webtools/plantcare/html/) [50] to predict the cis-acting elements. Cis-acting elements related to growth, stress and hormones were manually retained, and then submitted to TBtools v0.6696 for drawing.

\subsection{Chromosome Localization and Expression Profiles}

The chromosome distribution information of PgMAPKs and PgMAPKKs were displayed by TBtools. RNA-seq data of six pomegranate cultivars were downloaded from NCBI database, including "Dabenzi", "Tunisia", "Baiyushizi", "Wonderful”, "Nana", and "Black127" (Table 1 and Table S2). All RNA-Seq data were quality-controlled by fastp [49] to obtain clean reads. The index file was construct by Kallisto V0.44.0 [51] and then the normalized expression units (Transcripts Per Kilobase of exon model per Million mapped reads (TPM) values) of each gene were extracted by kallisto quant command. The final expression levels was from the TPM values that converted by $\log _{2}(\mathrm{TPM}+1)$. Then the Heatmap package in RStudio V3.6.1 [52] was used to draw the Heatmap of PgMAPKs and PgMAPKKs.

Table 1. RNA-Seq data of pomegranate.

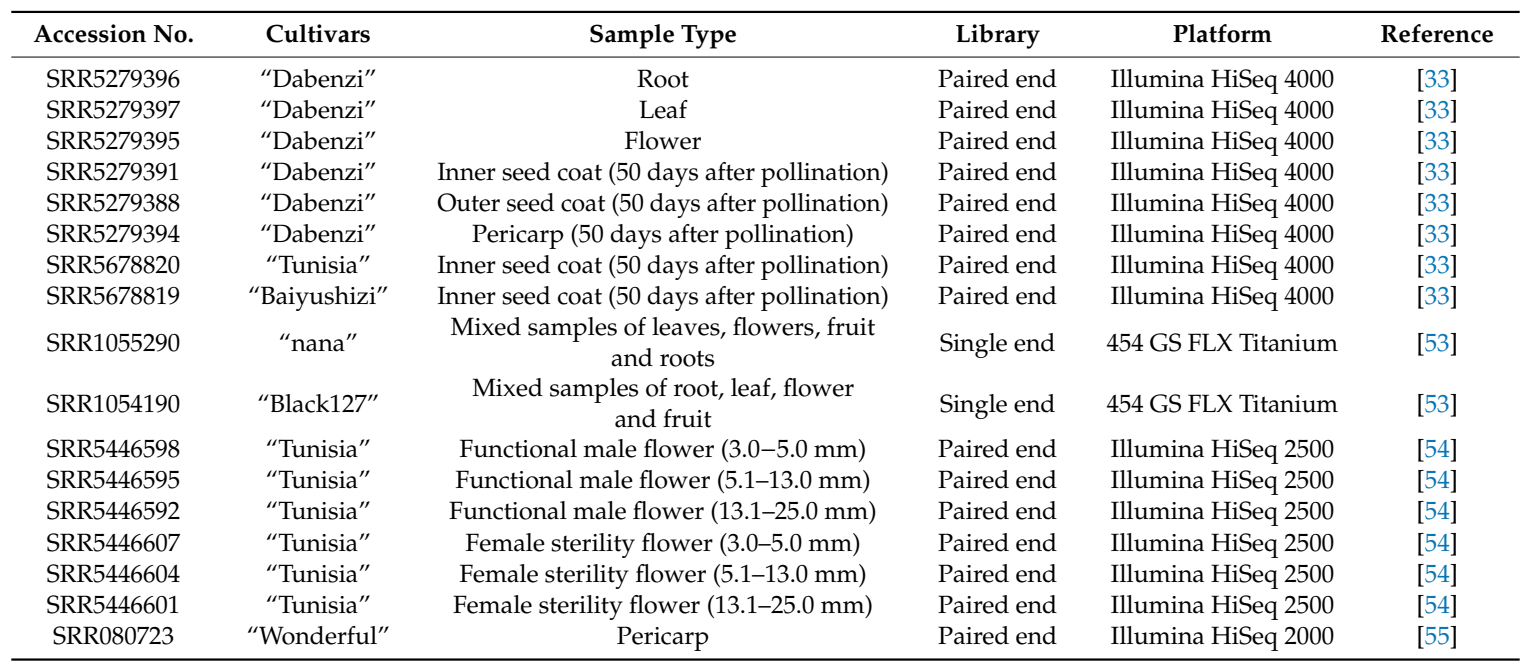

\section{Results}

\subsection{Identification and Sequence Analysis of PgMAPKs and PgMAPKKs}

According to the described method, 18 PgMAPKs and 9 PgMAPKKs were obtained from pomegranate whole genome, respectively (Table 2). Furthermore, the number of amino acids, 
molecular weight, theoretical pI of PgMAPKs and PgMAPKKs were analyzed by ExPASy online tool. The results showed that the molecular weight was between $34910.05 \sim 70420.74 \mathrm{Da}$, the isoelectric point was between 4.94 9.38, the protein length was within the range of 314 619 amino acids, the number of amino acids varied significantly. These data were similar to those reported in economic trees such as grape [56], banana [57], and apple [58]. However, the variations in physicochemical properties among the $P g M A P K s$ and $P g M A P K K s$ indicated that these genes may have subfunctionalization and new functionalization [59]. Chromosomal location analyses showed that 18 MAPKs and 9 MAPKKS presented on 7 chromosomes (chr1, chr2, chr3, chr4, chr6, chr7, chr8) (Table 2 and Figure 1).

Table 2. The information of $M A P K$ and $M A P K K$ gene family in pomegranate.

\begin{tabular}{|c|c|c|c|c|c|c|c|}
\hline $\begin{array}{l}\text { Gene } \\
\text { Name }\end{array}$ & Protein ID & Genomic Position & $\begin{array}{c}\text { Size } \\
\text { (aa) }\end{array}$ & $\begin{array}{l}\text { MW } \\
\text { (Da) }\end{array}$ & pIs & Types & Group \\
\hline PgMAPK1 & XP_031372466.1 & chr8:25215947 .. 25219536 & 615 & $68,952.19$ & 7.69 & TDY & $\mathrm{D}$ \\
\hline PgMAPK2 & XP_031382378.1 & chr2:26190661 . . 26195979 & 391 & $44,872.36$ & 5.57 & TEY & $\mathrm{A}$ \\
\hline PgMAPK3 & XP_031384487.1 & chr3:27987357 .. 27983062 & 484 & $55,597.84$ & 8.79 & TDY & $\mathrm{D}$ \\
\hline PgMAPK4 & XP_031387033.1 & chr3:6220495 .. 6221628 & 377 & $42,844.83$ & 8.90 & TGY & C \\
\hline PgMAPK5 & XP_031387034.1 & chr3:6229201 .. 6231072 & 435 & $48,521.45$ & 7.66 & TGY & C \\
\hline PgMAPK6 & XP_031387035.1 & chr3:6233547 .. 6234680 & 377 & $42,552.40$ & 9.23 & TGY & C \\
\hline PgMAPK7 & XP_031388383.1 & chr3:6647361 .. 6648512 & 383 & $43,266.50$ & 9.26 & TGY & C \\
\hline PgMAPK8 & XP_031389841.1 & chr4:494852 .. 498050 & 374 & $42,897.79$ & 6.11 & TEY & B \\
\hline PgMAPK9 & XP_031389944.1 & chr4:8712267 . . 8715865 & 380 & $43,399.50$ & 6.20 & TEY & B \\
\hline PgMAPK10 & XP_031392146.1 & chr4:18603577 . . 18604728 & 383 & $43,164.35$ & 9.36 & TGY & C \\
\hline PgMAPK11 & XP_031392360.1 & chr4:34805345 . . 34809858 & 617 & $70,420.74$ & 9.19 & TDY & $\mathrm{D}$ \\
\hline PgMAPK12 & XP_031399464.1 & chr6:27190634 . . 27192917 & 377 & $43,002.99$ & 4.94 & TEY & B \\
\hline PgMAPK13 & XP_031400536.1 & chr6:27163862 ... 27162051 & 375 & $42,968.25$ & 5.78 & TEY & A \\
\hline PgMAPK14 & XP_031402771.1 & chr1:54220111 . . 54215519 & 566 & $64,371.77$ & 8.76 & TDY & $\mathrm{D}$ \\
\hline PgMAPK15 & XP_031402779.1 & chr1:54220111 .. 54215513 & 564 & $64,243.64$ & 8.76 & TDY & $\mathrm{D}$ \\
\hline PgMAPK16 & XP_031404075.1 & chr7:28354650 . . 28351083 & 597 & $68,130.90$ & 9.35 & TDY & $\mathrm{D}$ \\
\hline PgMAPK17 & XP_031404901.1 & chr7:21504171 .. 21503431 & 372 & $42,781.79$ & 6.92 & TEY & $\mathrm{C}$ \\
\hline PgMAPK18 & XP_031406973.1 & chr7:3285226 . . 3281535 & 619 & $69,387.45$ & 8.06 & TDY & $\mathrm{D}$ \\
\hline MAPKK1 & XP_031374856.1 & chr8:13616418 .. 13612292 & 354 & $39,870.90$ & 5.96 & DIK & A \\
\hline MAPKK2 & XP_031374857.1 & chr8:13616418 .. 13612292 & 354 & $39,870.90$ & 5.96 & DIK & A \\
\hline MAPKK3 & XP_031381620.1 & chr2:14357511 .. 14354367 & 352 & $38,956.51$ & 5.49 & DLK & $\mathrm{A}$ \\
\hline MAPKK4 & XP_031383136.1 & chr2:2401332 . . 2404194 & 518 & $58,182.26$ & 5.76 & DIK & B \\
\hline MAPKK5 & XP_031383137.1 & chr2:2401332 . . 2404194 & 518 & $58,182.26$ & 5.76 & DIK & B \\
\hline MAPKK6 & XP_031383138.1 & chr2:2401664 ... 2404194 & 436 & $49,232.33$ & 6.04 & DIK & B \\
\hline MAPKK7 & XP_031388194.1 & chr3:13155229 .. 13156281 & 350 & $39,123.69$ & 9.38 & DIK & C \\
\hline MAPKK8 & XP_031393241.1 & chr4:1081579 ... 1082574 & 331 & $36,995.33$ & 8.31 & DIK & $\mathrm{D}$ \\
\hline MAPKK9 & XP_031406836.1 & chr7:3593726 . . 3594670 & 314 & $34,910.05$ & 8.35 & DIK & $\mathrm{D}$ \\
\hline
\end{tabular}
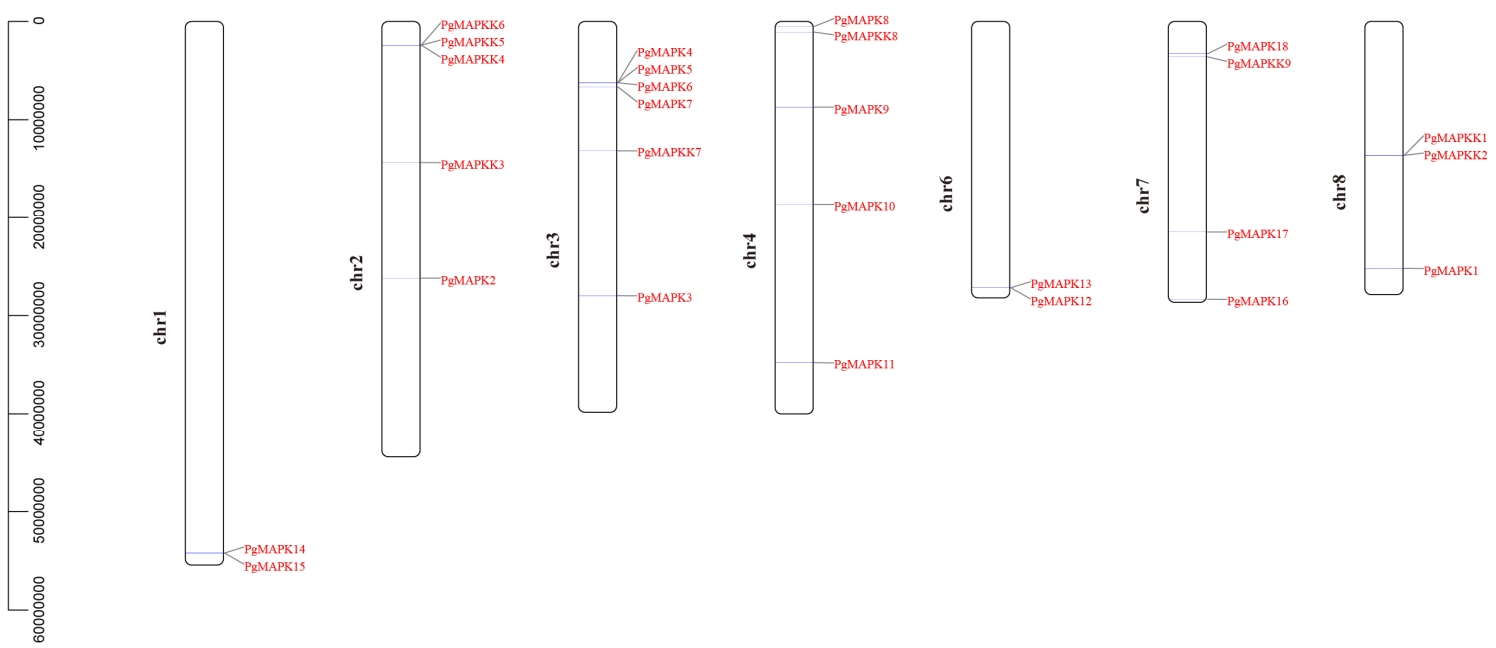

Figure 1. Positions of $P g M P K$ and $P g M P K K$ genes on the pomegranate chromosomes. Genes were mapped to the pomegranate chromosomes by TBtools. 


\subsection{Conserved Motif Analysis of PgMAPK and PgMAPKK Gene Family Members}

According to specific conserved motifs analysis, PgMAPKs and PgMAPKKs were found to have unique conserved motifs (Figures 1 and 2). The "VGTxxYMSPER" conserved motifs were found in 9 PgMAPKK genes, and the "T (E/D) YVxTRWYRAPE (L/V)" conserved motifs were contained in $18 P g M A P K$ genes (Figure 2). Through multiple sequence alignment of the protein sequences of $P g M A P K$ family genes, "T-loop" motifs were detected in the domain (Figure 3). There was an ATP phosphorylation site catalyzed by "TxY", which plays an important role in the function of PgMAPKs. According to previous studies of model plants, the PgMAPK gene family can also be divided into four groups (A, B, C, and D) and can be divided into subtypes of "TDY" and "TEY" according to different "TxY" phosphorylation sites (Table 1). In addition, phosphorylation domains with "S/T-XXXXX-S/T" and an anchor site with "-D (L/I/V) K-" were found in PgMAPKKs (Figure 3). PgMAPKKs were also divided into four groups (A, B, C and D) (Table 1) based on results reported in the Arabidopsis thaliana [60].

\subsection{Phylogenetic Relationship of PgMAPKs and PgMAPKKs}

In order to explore the evolutionary relationship toward PgMAPK and PgMAPKK proteins, the predicted protein sequences of 18 PgMAPKs, 9PgMAPKKs, 20 AtMAPKs, and 10AtMAPKKs from Arabidopsis were subjected to a multiple sequence alignment using the MEGA7. The N-J (Neighbor-Joining) method was then used to construct an unrooted phylogenetic tree. As shown in Figure 4, the phylogenetic tree divided PgMAPKs and PgMAPKKs into four groups (A, B, C, D). The most abundant of MAPK gene family members were in group $D(7)$, followed by group $C$ (6), group B (3) and group A (2). This result was consistent with previous studies on Arabidopsis [14], rice [15], and tomato [61]. The number of MAPKK gene family was less than that of $M A P K K$, so there was no significant difference in the number of each group. Three (PgMAPKK1, PgMAPKK2, PgMAPKK3), three (PgMAPKK4, PgMAPKK5, PgMAPKK6), one (PgMAPKK7) and two (PgMAPKK8, PgMAPKK9) $P g M A P K K$ genes belonged to groups $\mathrm{A}, \mathrm{B}, \mathrm{C}$, and D respectively. The ratio of PgMAPKKS to PgMAPKs was about 1:2, which was in accordance with that in other plant (Table 3). In summary, compared with these model plants, the quantity and grouping status of MAPKs and MAPKKs were highly conserved in pomegranate (Figure 4, Table 3).
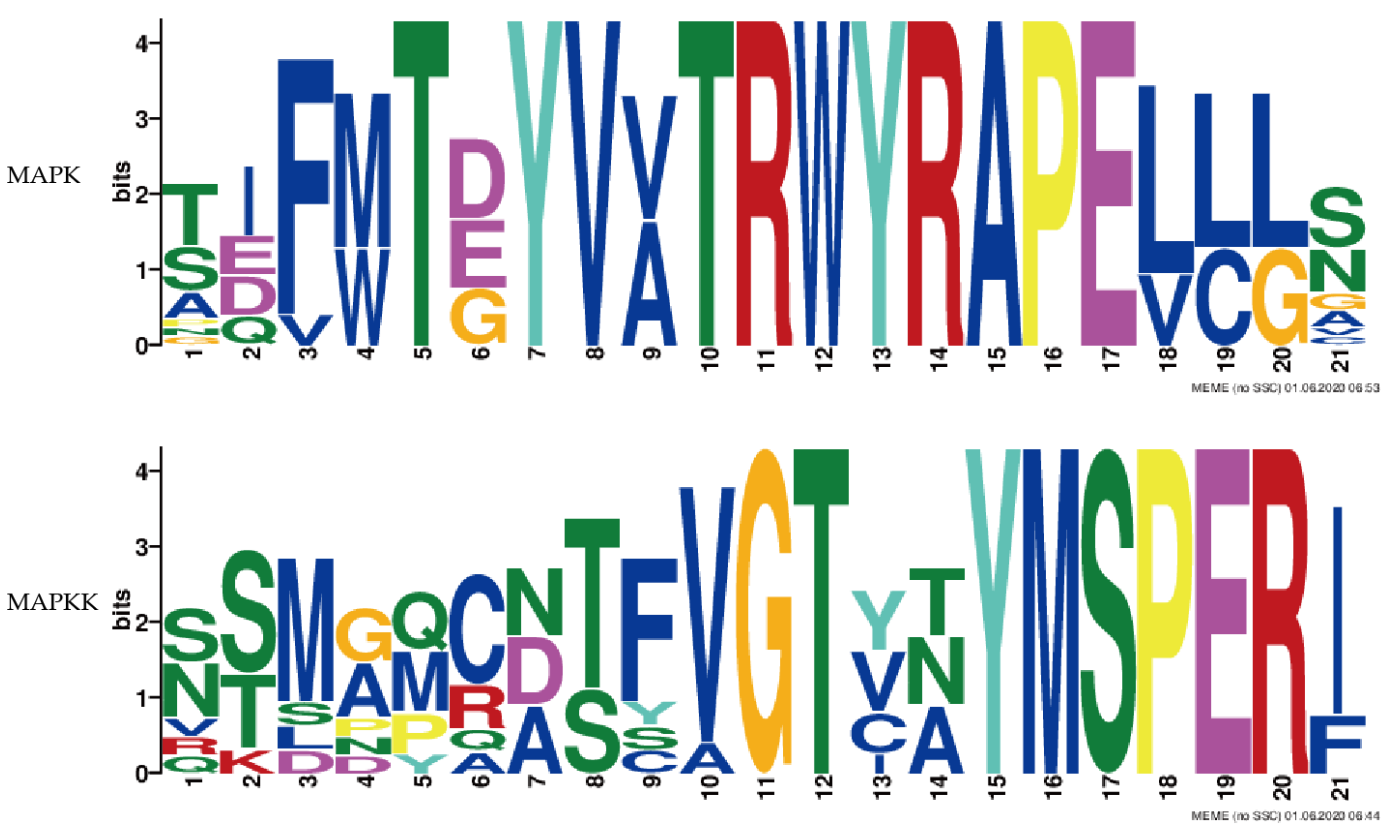

Figure 2. The specific conserved motif of $M A P K$ and $M A P K K$ gene in pomegranate. 

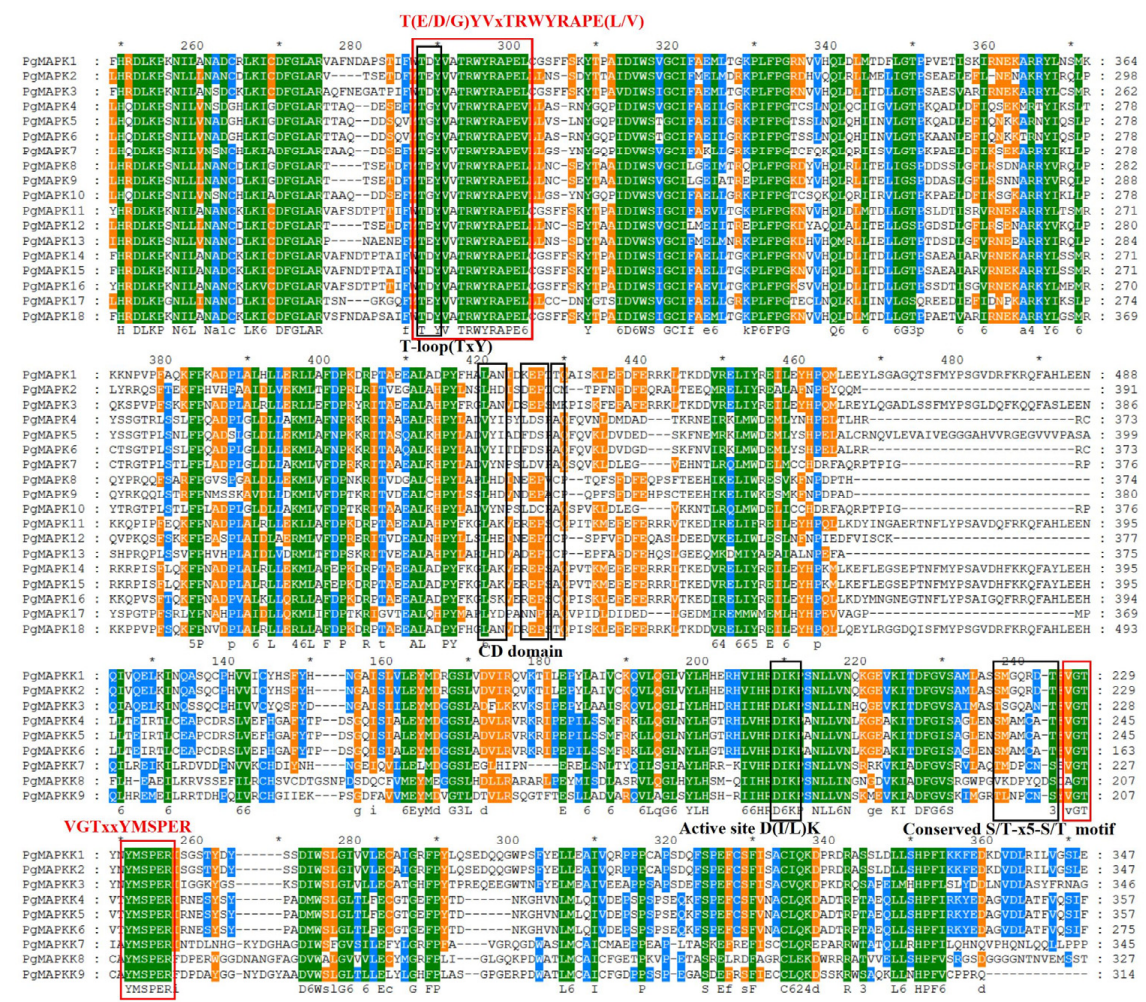

Figure 3. Sequence multiple alignment and conserved motifs analysis of $P g M A P K$ and $P g M A P K K$ genes.

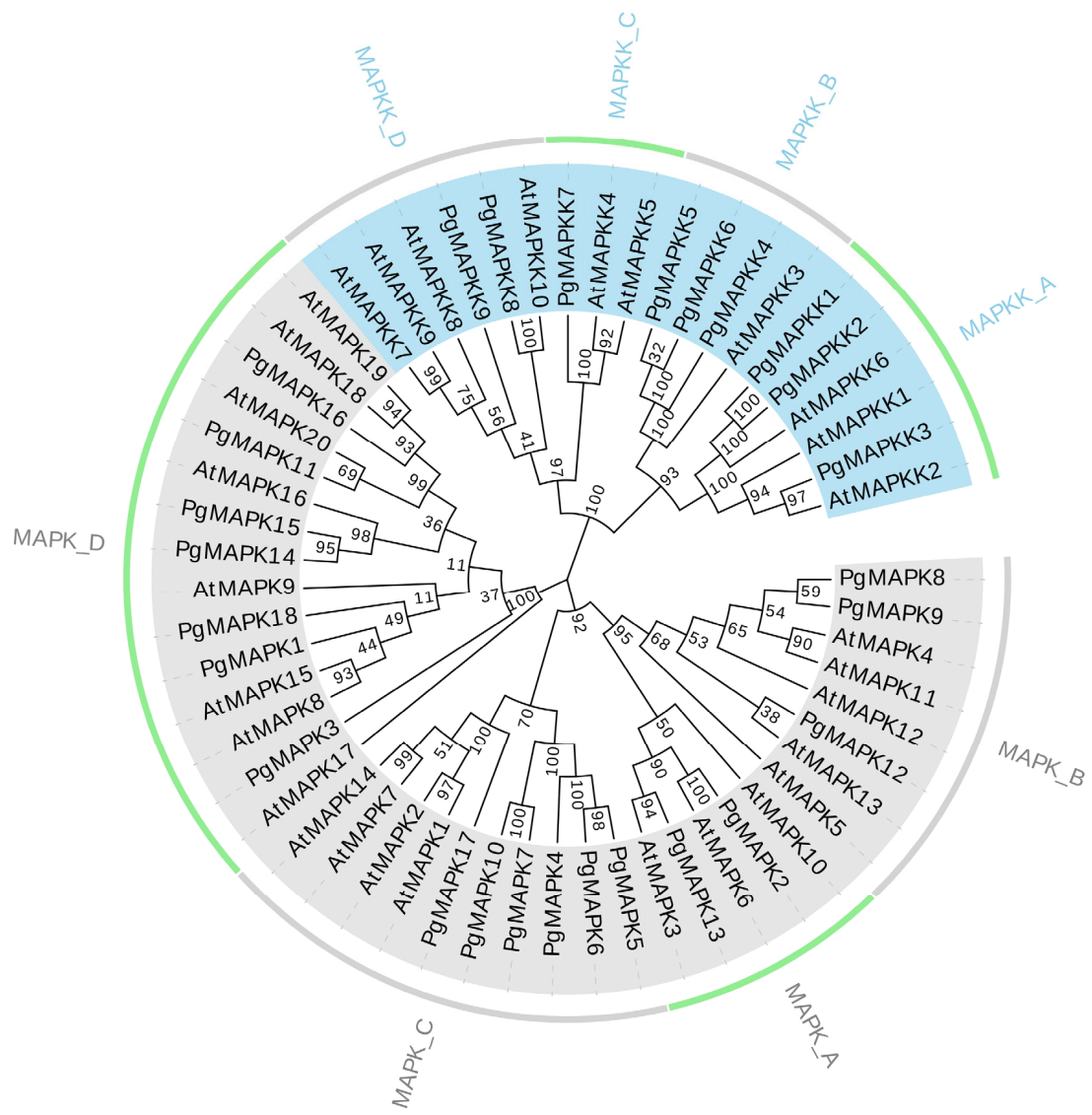

Figure 4. The phylogenetic tree of the MAPK and MAPKK gene family in pomegranate and Arabidopsis thaliana. 
Table 3. The number of the $M A P K$ and $M A P K K$ gene family in Pomegranate and other plants.

\begin{tabular}{cccccccc}
\hline $\begin{array}{c}\text { Gene } \\
\text { Family }\end{array}$ & Species & GroupA & GroupB & GroupC & GroupD & Total & Reference \\
\hline \multirow{5}{*}{ MAPK } & Pomegranate & 2 & 3 & 6 & 7 & 18 & \\
& Chinese jujube & 2 & 1 & 2 & 5 & 11 & {$[10]$} \\
& Arabidopsis & 3 & 5 & 4 & 8 & 20 & {$[14]$} \\
& Rice & 2 & 1 & 2 & 10 & 15 & {$[15]$} \\
& Brachypodium distachyon & 2 & 2 & 3 & 9 & 16 & {$[17]$} \\
& Maize & 4 & 2 & 2 & 11 & 10 & {$[18]$} \\
& Apple & 5 & 6 & 5 & 10 & 26 & {$[58]$} \\
& Poplar & 4 & 4 & 4 & 9 & 21 & {$[60]$} \\
& Tomato & 3 & 4 & 2 & 7 & 16 & {$[61]$} \\
& Mulberry & 2 & 3 & 2 & 3 & 10 & {$[62]$} \\
Bread wheat & 7 & 3 & 8 & 36 & 54 & {$[3]$} \\
\hline & Pomegranate & 3 & 3 & 1 & 2 & 9 & \\
& Chinese jujube & 2 & 1 & 0 & 2 & 5 & {$[10]$} \\
& Arabidopsis & 3 & 1 & 2 & 4 & 10 & {$[14]$} \\
& Rice & 2 & 1 & 2 & 3 & 8 & {$[15]$} \\
& Brachypodium distachyon & 2 & 3 & 2 & 5 & 12 & {$[17]$} \\
& Apple & 3 & 1 & 2 & 3 & 9 & {$[58]$} \\
& Poplar & 3 & 1 & 2 & 5 & 11 & {$[60]$} \\
\hline
\end{tabular}

\subsection{Gene Structure Analysis of PgMAPKs and PgMAPKKs}

Gene structure analysis was supposed to provide valuable information about evolutionary and duplication events among gene families. We found that most members of the same group share similar exon/intron structures and conserved motifs. In the PgMAPKs gene family, each group showed different structural characteristics. In group A, PgMPK2 and PgMAPK13 were composed of 6 exons with the longer introns. Six exons were also found in same group of MAPKs in Arabidopsis, poplar and tomato. PgMPK8, PgMAPK9, and PgMAPK12 in group B had 6 exons, which was also consistent with the results of studies on tomato and poplar studies. In group C, PgMAPK5 and PgMAPK17 were only composed of two exons, and the size of each exon was strictly conservative. Compared with the highly conserved structural pattern in group C, the exon and intron distribution of $P g M P K s$ in group D was more complex, exhibiting a diverse pattern. For example, PgMPK1, PgMAPK18 had 11 exons, while PgMAPK11, PgMAPK14, PgMAPK15, and PgMAPK16 had 10 exons, and PgMAPK3 only had 9 (Figure 5). Although there were slight differences in exon lengths, it was clear that the structural patterns of exons well conserved not only between close paralogs, but also between the PgMAPKs that apparently diverged following earlier duplication events.

The $P g M A P K K$ gene showed two distinct structural patterns (Figure 5) which were quite similar to the MAPKK gene in Arabidopsis and poplar. PgMAPKK7 in group C and PgMAPKK8, PgMAPKK9 in group D both had less introns and extrons, whereas the PgMAPKKs in group A and group $\mathrm{B}$ possessed more exon and intron junctions. In group A, PgMAPKK1 and PgMAPKK2 had 7 exons, while $P g M A P K K 3$ had 8 exons. Consistent with other plants, PgMAPKK1 and PgMAPKK2 shared strong conservation of exonic length. As shown in Figure 5, there were highly consistency of gene structure among the three genes (PgMAPKK4, PgMAPKK5, and PgMAPKK6) in group B. 


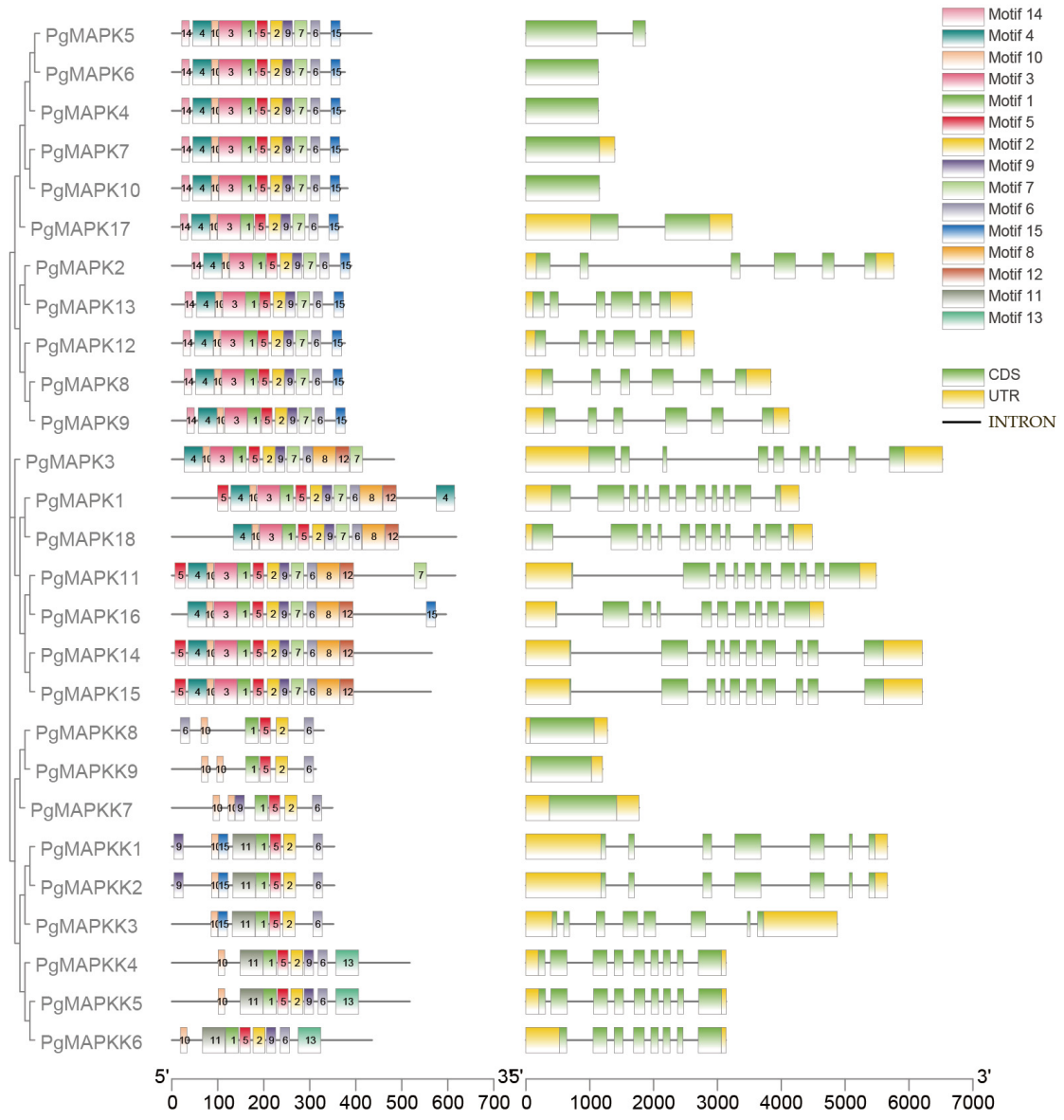

Figure 5. The exon/intron structure of $P g M A P K$ and $P g M A P K K$ genes. Introns and exons are represented by black lines and green boxes respectively. Note: The structure was analyzed combined phylogenetic trees and motif patterns from the perspective of evolution.

\subsection{Cis-Acting Element Prediction of PgMAPKs and PgMAPKKs}

We extracted upstream 2.0 KB of genome sequence for the cis-acting elements analysis. And hundreds of possible cis-acting elements downloaded from the Platcare database (Table S3). After screening, 25 cis-acting elements with clear functional information were retained (Table S4). Among them, we found that a total of 6 elements were related to stress, 9 elements were related to growth and development, and the remaining 10 elements were related to hormones (Table 4). As shown in Table 3, elements named ARE, LTR, and MBS were present in 20, 18 and 17 genes, respectively. These results indicated that $P g M A P K$ and $P g M A P K K$ genes were widely involved in hypoxia, low temperature and drought stress of pomegranate. Furthermore, WUN-motif was found in six genes, indicating that these genes involved in the external damage mechanism of pomegranate. The elements related to plant growth and development mainly included circadian rhythm, meristem, palisade mesophytic differentiation and endosperm. Notably, MBSI elements were found in five genes (PgMAPK2, PgMAPK4, PgMAPK8, PgMAPK14, and PgMAPK15), suggesting that these genes are involved in the mechanism of flavonoid synthesis in pomegranate. In addition, the cis-acting elements related to various hormone reactions (such as auxin, ethylene, salicylic acid, MeJA, GA3), indicating that PgMAPKs and PgMAPKKs were deeply involved in signal transduction of endogenous and exogenous hormone networks in pomegranate. To sum up, the various cis-acting elements in the gene promoter region suggested that the PgMAPK and $P g M A P K K$ gene family plays a crucial role in its growth and development and stress adaptation (Table 4 and Figure 6). 
Table 4. Characteristics of cis-acting regulatory elements presented in the promoter regions of $P g M A P K$ and PgMAPKK genes.

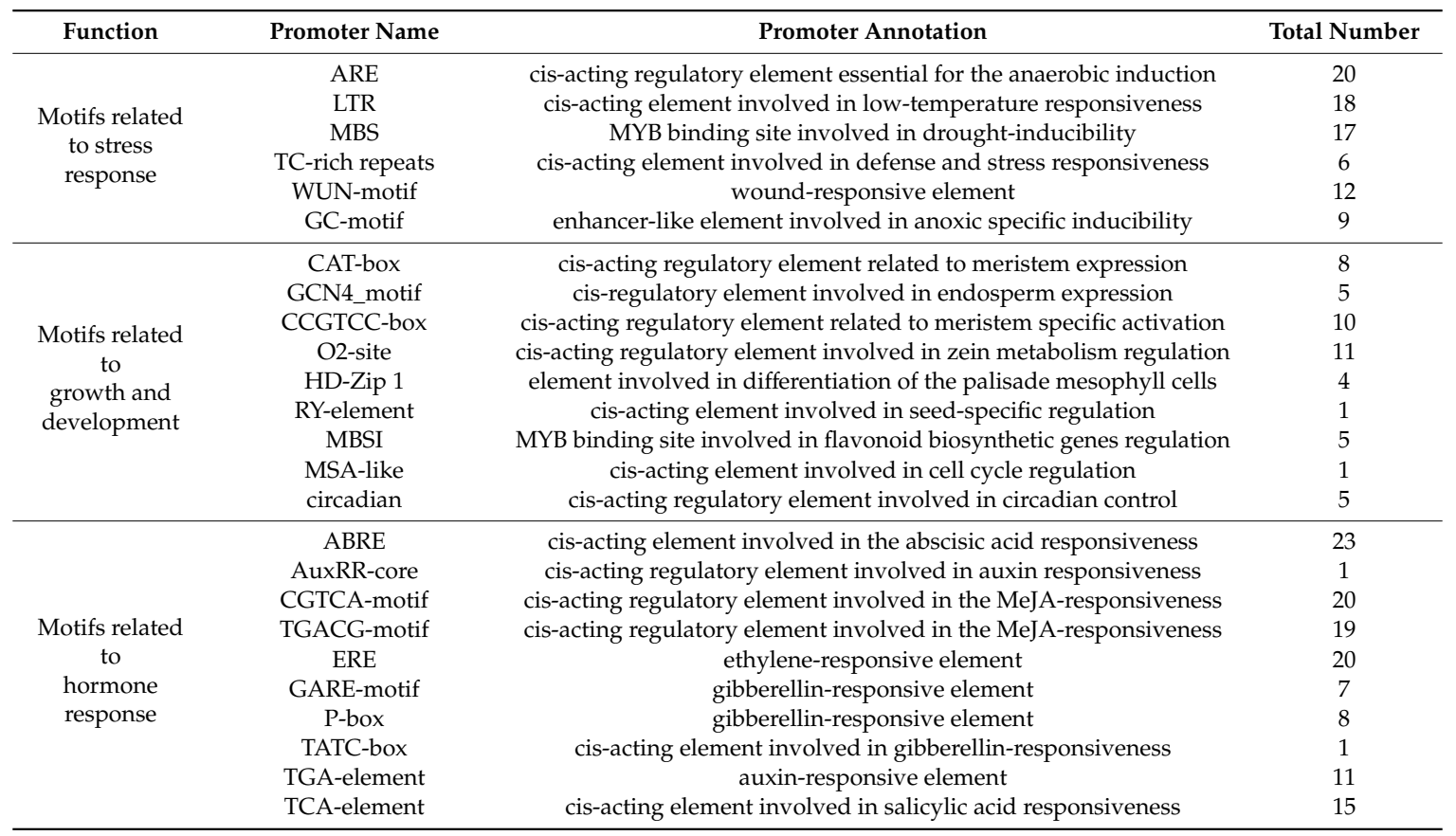
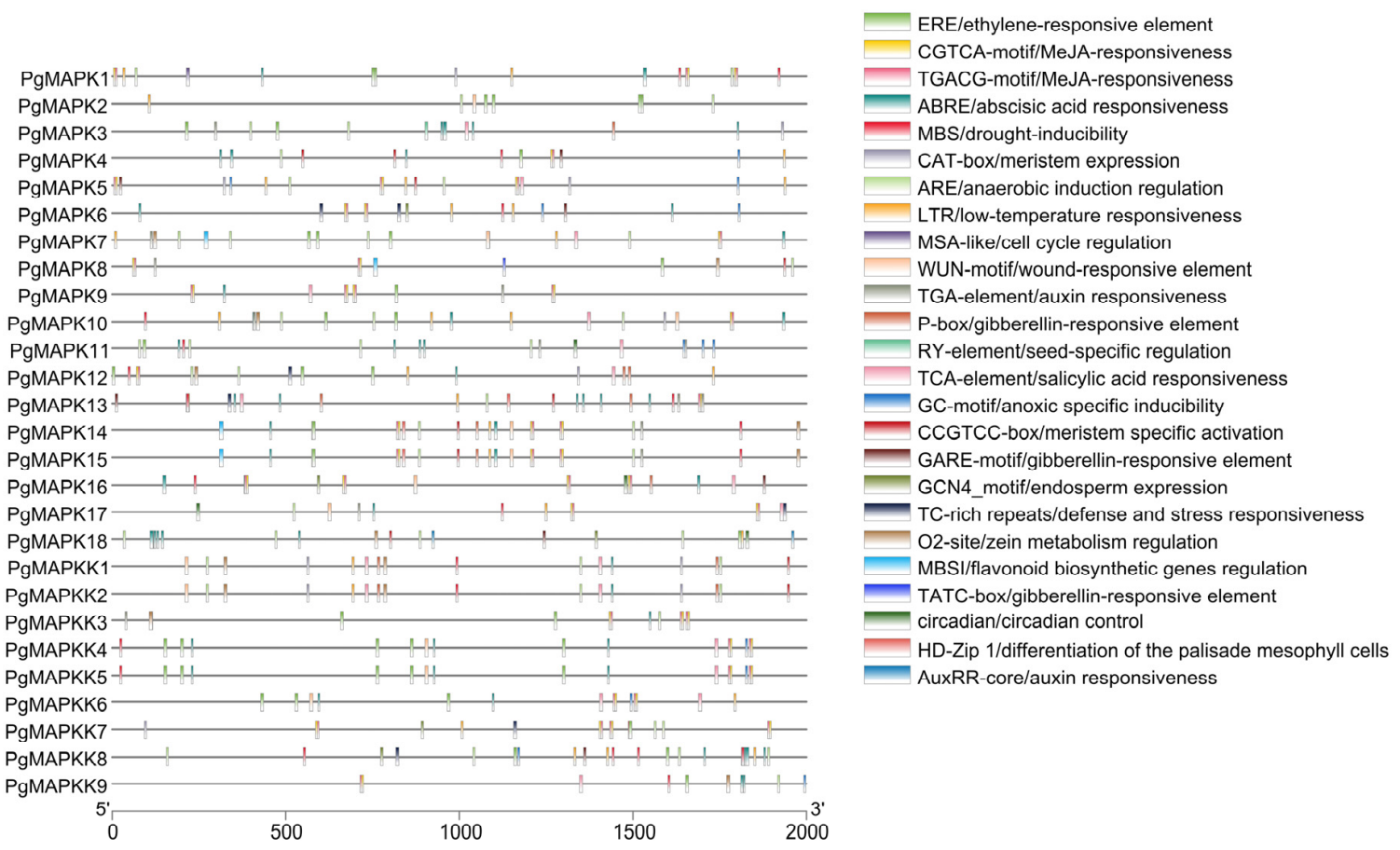

Figure 6. Promoter cis-acting element of $M A P K$ and $M A P K K$ genes in pomegranate.

\subsection{Expression Pattern of PgMAPKs and PgMAPKKs}

We used the online RNA-seq data to explore the expression patterns of MAPK and MAPKK genes in pomegranates at different developmental stages. The results showed that these 27 genes were expressed in at least one tissue organ or stage of development (Figure 6). Compared with other genes, PgMAPK13 was highly expressed in root, flower and seed coat, while PgMAPK4, PgMAPK5, PgMAPK6, PgMAPK7, PgMAPK8, PgMAPK10 had a less expression level. PgMAPK9, PgMAPK12 and $P g M A P K K 7$ was expressed in all except pericarp as shown in Figure 7A. A high PgMAPKK9 and 
PgMAPK13 expression level was found in in inner seed coat after pollination for 50 days. PgMAPKK3 and $P g M A P K K 9$ expressed significantly variously during the development of functional male flower and female sterility flower as illustrated in Figure 7C. The expression patterns demonstrated that the expression level of each gene was highly variable, suggesting that these genes play an indispensable role in regulating plant growth and development.
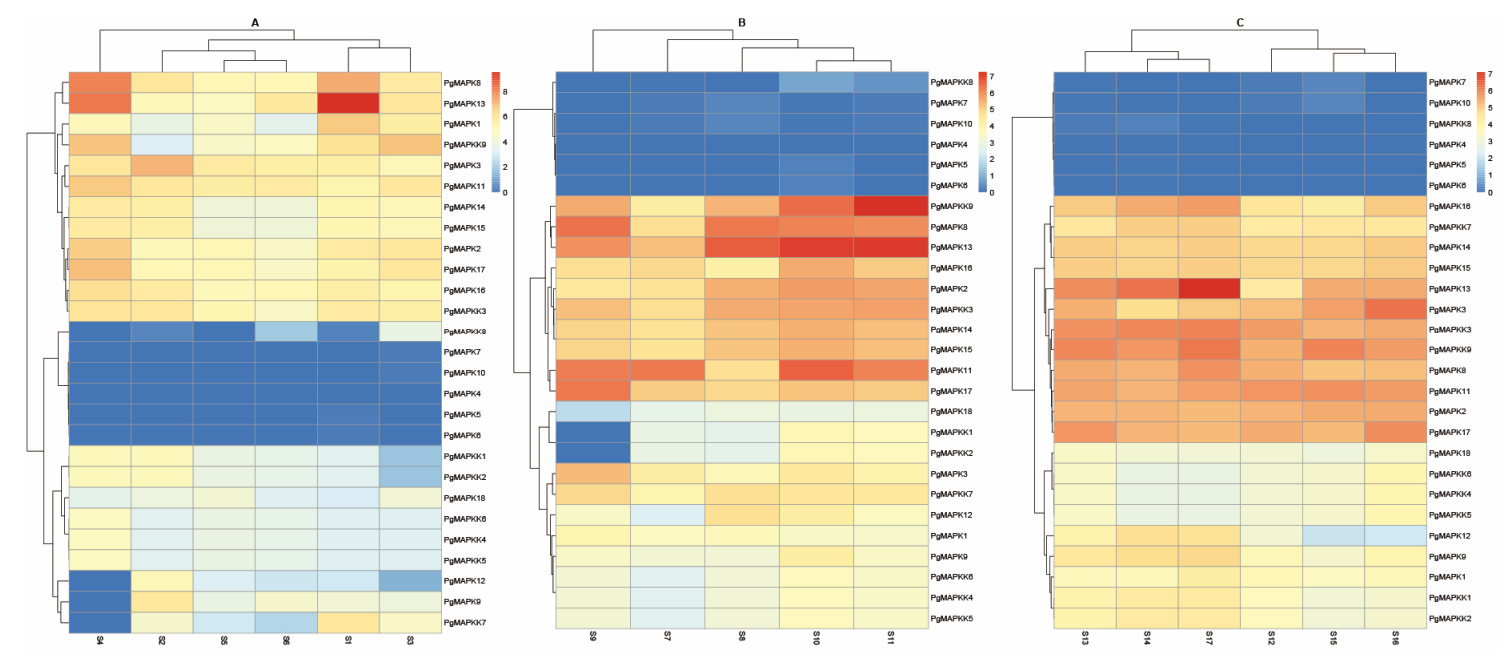

Figure 7. Heatmap of $P g M A P K$ and $P g M A P K K$ gene expression in different tissues. (A) showed the expression difference of different tissues; (B) illustrated difference in inner and outer seed coat and pericarp after pollination for 50 days; (C) displayed the expression under different stages of flower development in cultivar "Tunisia”. Note: S1: Root; S2: Leaf; S3: Flower; S4: Pericarp; S5: Mixed sample of leaves, flowers, fruit, roots of "nana"; S6: Mixed sample of leaves, flowers, fruit, roots of "Black127"; S7: Inner seed coat (50 days after pollination); S8: Outer seed coat (50 days after pollination); S9: (50 days after pollination); S10: Inner seed coat of "Tunisia" (50 days after pollination); S11: Inner seed coat of "Baiyushizi" (50 days after pollination); S12: Functional male flower (13.1-25.0 mm); S13:functional male flower (5.1-13.0 mm); S14: Functional male flower (3.0-5.0 mm); S15: Female sterility flower (13.1-25.0 mm); S16: Female sterility flower (5.1-13.0 mm); S17: Female sterility flower (3.0-5.0 mm); S1-S4, S7-S9 and S12-S17 are cultivar "Dabenzi".

\section{Discussion}

Generally, plants responded to various biological and abiotic stresses through physiological, biochemical and even molecular changes to resist and adapt them [59]. As an important protein kinases group, MAPKs and MAPKKs can transfer extracellular signals to intracellular signals in plant growth and development, hormone regulation and stress response [63,64]. To date, MAPK and $M A P K K$ gene family have been identified and functionally characterized in several model plants and numerous economic trees. However, the MAPK and MAPKK gene family in pomegranate has not been reported previously.

In this study, we first identified 18 MAPKs and 9 MAPKKs in pomegranate at genome-wide level. The numbers of these family members were similar to those found in other plant species, such as Ziziphus jujuba (11/5) [10], Arabidopsis thaliana (20/10) [13,14], Oryza sativa (17/8) [15,16], Brachypodium distachyon (16/12) [17], Malus Domestica (26/9) [58], Populus (21/11) [60], Solanum lycopersicum (16/5) [61], Triticum aestivum (54/18) [3], Capsicum annuum (19/5) [65], Cucumis sativus (14/6) [66], Citrullus lanatus (15/6) [67], and Jatropha curcas (12/5) [68].

Figure 1 displayed a scattered distribution of PgMAPKs and PgMAPKKs on the 7 chromosomes of Punica granatum. The chromosome distribution pattern showed that the PgMAPK or PgMAPKK genes density was relatively high in certain chromosomes. Regions containing 4 or more genes in the range of $200 \mathrm{~kb}$ or less can be regarded as gene clusters [69]. Only one gene cluster with four members in $P g M A P K$ gene family and no other gene cluster was found in PgMAPKs (Figure 1). However, given 
that our clustering criteria was relaxed to at least two genes, 7 clusters would be found ( $63.6 \%$ of MAPK and MAPKK family members appeared in the cluster). In addition, we also found that although the $P g M A P K K 3$ and the gene cluster consisting of PgMAPKK4, PgMAPKK5, and PgMAPKK6 were all located on the same chromosome, they were physically far apart, which was consistent with the result of phylogenetic and multiple alignment analysis.

$P g M A P K s$ were divided into three subtypes of "TDY", "TEY", and "TGY" according to different "TxY" phosphorylation sites by multiple sequence alignment (Table 2, Figure 3). Interestingly, all $P g M A P K s$ in group $C$ had a "TGY" motif except $P g M A P K 17$. The "TGY" activation loop was similar to P38 MAPKs in mammals, rather than the T(E/D)Y motif commonly in plants [19]. As far as we know, the same results were also found in wheat, where TaMPK25 also carries a TGY activating loop [70]. Furthermore, there were confirmed results included MAPKs in group B mainly involved in cell division and environmental stress response [66]. Therefore, PgMAPK8, PgMAPK9, and PgMAPK12 may also response to various stress. MAPKKs in pomegranate were phosphorylated by "S/T-XXXXX-S/T" and anchored by "-D(L///V) K-". Due to its wide range of functions, many MAPKK genes have been cloned recently, such as AtMKK1 and AtMKK2-5 of Arabidopsis thaliana, SiMKK of Alfalfa, MEK1 of tomato, NTMEK1-2 of tobacco and ZmMEK1 of maize [7].

Since highly differentiated sequences may responsible for regulatory diversity of MAPK and MAPKK protein, we constructed a phylogenetic tree based on the predicted MAPK and MAPKK proteins of pomegranate and Arabidopsis thaliana. Four groups were separated in phylogenetic tree, which were named following previous studies [67]. The members in each group shared similar intron-exon structures. Consistent with previous studies, these data indicate similar origins and evolutionary patterns of $M A P K$ and $M A P K K$ genes in plants. It is possible that original family member had experienced replication events prior to the eudicot-monocot divergence $[58,65]$.

The MAPK cascade genes have been studied to interact with signaling pathways mediated by hormone responsive cis-acting elements such as SA, JA, and ethylene [71]. Hormone responsive elements such as MeJA-responsive element (CGTCA-motif and TGACG-motif) [72], ethylene-responsive ERE element [73], gibberellin-responsive element (GARE-motif, P-box element, TATC-box) [74], abscisic acid-responsive ABRE [75], and salicylic acid-responsive TCA element [76] were widely found in the promoters of $P g M A P K$ and $P g M A P K K$ genes in Punica ganatum. These results indicated that they were widely involved in pomegranate life cycles [77].

Previous studies have confirmed that the response of plants to the development and biological process are greatly regulated at the transcription level $[66,73]$. RNA-seq data showed that the expression levels of $P g M A P K s$ and $P g M A P K K s$ varied greatly in different tissues, which was consistent with the research of pepper and other species [65]. Obviously, some PgMAPK and PgMAPKK genes were highly expressed while others expressed at a low level or not expressed, suggesting their diverse functions in pomegranate growth and development [78]. For example, MAPKs in rice can regulate auxin signaling and cell cycle-related gene expression of root under cadmium stress [79].

Our results will lay the foundation for the functional characterization of MAPK and MAPKK gene family, and further understanding of the structure-function relationship among gene members. In addition, our study also provides comprehensive information and new insights into the evolution and differentiation of $P g M A P K$ and PgMAPKK genes. These studies may provide a molecular basis for key agronomic traits, developmental, and other physiological processes in pomegranates.

\section{Conclusions}

In this study, a total of $18 P g M A P K$ and $9 P g M A P K K$ genes were identified in pomegranate and their phylogenetic relationships were explored. The gene structure of each group members was similar. PgMAPKs and PgMAPKKs may participate in the apical meristems, flower organ and fruit development, and the same group may have the similar expression pattern. These results lay the foundation for function studies on PgMAPKs and PgMAPKKs during their evolutionary process. 
Supplementary Materials: The following are available online at http://www.mdpi.com/2073-4395/10/7/1015/s1, Fasta file S1: MAPK and MAPKK protein sequences of Arabidopsis thaliana, Fasta file S2: MAPK and MAPKK protein sequences of pomegranate (Punica granatum L.), Table S1: IDs of MAPK and MAPKK gene sequences of Arabidopsis thaliana. Table S2: RNA-seq origin data of 18 PgMAPKs and 9 PgMAPKKs; Table S3: All cis-acting elements of 18 PgMAPKs and 9 PgMAPKK, Table S4: 25 cis-acting elements retained18 PgMAPKs and 9 PgMAPKKs.

Author Contributions: Conceptualization, Y.R. and Z.Y.; methodology, Y.R.; formal analysis, Y.R.; investigation, Y.R. and D.G.; writing_-original draft preparation, Y.R.; writing—review and editing, Y.R., D.G., J.D., L.G. and Z.Y.; supervision, Z.Y.; funding acquisition, Z.Y. All authors have read and agreed to the published version of the manuscript.

Funding: This research was funded by the Tibet Autonomous Region Natural Science Foundation (XZ201019ZRG-153); the Initiative Project for Talents of Nanjing Forestry University [GXL2014070, GXL2018032], the Priority Academic Program Development of Jiangsu High Education Institutions [PAPD], the National Natural Science Foundation of China (31901341), the Natural Science Foundation of Jiangsu Province [BK20180768].

Conflicts of Interest: The authors declare no conflict of interest.

\section{References}

1. Nakagami, H.; Pitzschke, A.; Hirt, H. Emerging MAP kinase pathways in plant stress signalling. Trends Plant Sci. 2005, 10, 339-346. [CrossRef]

2. Zhan, H.; Hong, Y.; Zhao, X.; Wang, M.; Weining, S.; Nie, X. Genome-wide identification and analysis of MAPK and MAPKK gene families in bread wheat (Triticum aestivum L.). Genes 2017, 8, 10. [CrossRef]

3. Shen, H.; Liu, C.; Zhang, Y.; Meng, X.; Zhou, X.; Chu, C.; Wang, X. OsWRKY30 is activated by MAP kinases to confer drought tolerance in rice. Plant Mol. Biol. 2012, 80, 241-253. [CrossRef]

4. Raina, S.K.; Wankhede, D.P.; Jaggi, M.; Singh, P.; Jalmi, S.K.; Raghuram, B.; Sheikh, A.H.; Sinha, A.K. CrMPK3, a mitogen activated protein kinase from Catharanthus roseusand its possible role in stress induced biosynthesis of monoterpenoid indole alkaloids. BMC Plant Biol. 2012, 12, 134. [CrossRef] [PubMed]

5. Tena, G.; Asai, T.; Chiu, W.; Sheen, J. Plant mitogen-activated protein kinase signaling cascades. Curr. Opin. Plant Biol. 2001, 4, 392-400. [CrossRef]

6. Zhou, H.; Ren, S.; Han, Y.; Zhang, Q.; Qin, L.; Xing, Y. Identification and analysis of mitogen-activated protein kinase (MAPK) cascades in Fragaria vesca. Int. J. Mol. Sci. 2017, 18, 1766. [CrossRef] [PubMed]

7. Kong, X.; Pan, J.; Zhang, D.; Jiang, S.; Cai, G.; Wang, L.; Li, D. Identification of mitogen-activated protein kinase kinase gene family and MKK-MAPK interaction network in maize. Biochem. Biophys. Res. Commun. 2013, 441, 964-969. [CrossRef] [PubMed]

8. Jonak, C.; Ökrész, L.; Bögre, L.; Hirt, H. Complexity, cross talk and integration of plant MAP kinase signalling. Curr. Opin. Plant Biol. 2002, 5, 415-424. [CrossRef]

9. Zhang, T.; Liu, Y.; Yang, T.; Zhang, L.; Xu, S.; Xue, L.; An, L. Diverse signals converge at MAPK cascades in plant. Plant Physiol. Biochem. 2006, 44, 274-283. [CrossRef]

10. Liu, Z.; Zhang, L.; Xue, C.; Fang, H.; Zhao, J.; Liu, M. Genome-wide identification and analysis of MAPK and MAPKK gene family in Chinese jujube (Ziziphus jujuba Mill.). BMC Gen. 2017, 18, 855. [CrossRef]

11. Kazuya, I.; Ichimura, K.; Shinozaki, K.; Tena, G.; Sheen, J.; Henry, Y.; Champion, A.; Kreis, M.; Zhang, S.; Hirt, H.; et al. Mitogen-activated protein kinase cascades in plants: A new nomenclature. Trends Plant Sci. 2002, 7, 301-308. [CrossRef]

12. Moustafa, K.; AbuQamar, S.; Jarrar, M.; Al-Rajab, A.J.; Trémouillaux-Guiller, J. MAPK cascades and major abiotic stresses. Plant Cell Rep. 2014, 33, 1217-1225. [CrossRef]

13. Andreasson, E.; Ellis, B. Convergence and specificity in the Arabidopsis MAPK nexus. Trends Plant Sci. 2010, 15, 106-113. [CrossRef] [PubMed]

14. Rasmussen, M.; Roux, M.; Petersen, M.; Mundy, J. MAP kinase cascades in Arabidopsis innate immunity. Front. Plant Sci. 2012, 3, 169. [CrossRef] [PubMed]

15. Pandhari, W.D.; Misra, M.; Singh, P.; Sinha, A.K.; Provart, N.J. Rice mitogen activated protein kinase Kinase and mitogen activated protein kinase interaction network revealed by in-silico docking and yeast two-hybrid approaches. PLoS ONE 2013, 8, e65011. [CrossRef]

16. Rao, K.P.; Tambi, R.; Kundan, K.; Badmi, R.; Krishna, S.A. In silico analysis reveals 75 members of mitogen-activated protein kinase kinase kinase gene family in rice. DNA Res. 2010, 3, 139-153. [CrossRef] 
17. Feng, K.; Liu, F.; Zou, J.; Xing, G.; Deng, P.; Song, W.; Tong, W.; Nie, X. Genome-wide identification, evolution, and co-expression network analysis of mitogen-activated protein kinase kinase kinases in Brachypodium distachyon. Front. Plant Sci. 2016, 7, 1400. [CrossRef] [PubMed]

18. Liu, Y.; Zhang, D.; Wang, L.; Li, D. Genome-wide analysis of mitogen-activated protein kinase gene family in maize. Plant Mol. Biol. Rep. 2013, 31, 1446-1460. [CrossRef]

19. Cui, L.; Yang, G.; Yan, J.; Pan, Y.; Nie, X. Genome-wide identification, expression profiles and regulatory network of MAPK cascade gene family in barley. BMC Gen. 2019, 20, 750. [CrossRef]

20. Ren, D.; Yang, K.Y.; Li, G.J.; Liu, Y.; Zhang, S. Activation of Ntf4, a tobacco mitogen-activated protein kinase, during plant defense response and its involvement in hypersensitive response-like cell death. Plant Physiol. 2006, 141, 1482-1493. [CrossRef]

21. Ichimura, K.; Casais, C.; Peck, S.C.; Shinozaki, K.; Shirasu, K. MEKK1 is required for MPK4 activation and regulates tissue-specific and temperature-dependent cell death in Arabidopsis. J. Biol. Chem. 2006, 281, 36969-36976. [CrossRef] [PubMed]

22. Suarez-Rodriguez, M.C.; Adams-Phillips, L.; Liu, Y.; Wang, H.; Su, S.; Jester, P.J.; Zhang, S.; Bent, A.F.; Krysan, P.J. MEKK1 is required for flg22-induced MPK4 activation in Arabidopsis plants. Plant Physiol. 2007, 143, 661-669. [CrossRef] [PubMed]

23. Asai, T.; Tena, G.; Plotnikova, J.; Willmann, M.R.; Chiu, W.; Gomez-Gomez, L.; Boller, T.; Ausubel, F.M.; Sheen, J. MAP kinase signalling cascade in Arabidopsis innate immunity. Nature 2002, 415, 977-983. [CrossRef] [PubMed]

24. De Zelicourt, A.; Colcombet, J.; Hirt, H. The role of MAPK modules and ABA during abiotic stress signaling. Trends Plant Sci. 2016, 21, 677-685. [CrossRef]

25. Wang, J.; Ding, H.; Zhang, A.; Ma, F.; Cao, J.; Jiang, M. A novel mitogen-activated protein kinase gene in maize (Zea mays), ZmMPK3, is involved in response to diverse environmental cues. J. Integr. Plant Biol. 2010, 52, 442-452. [CrossRef]

26. Xiong, L.; Yang, Y. Disease resistance and abiotic stress tolerance in rice are inversely modulated by an abscisic acid-inducible mitogen-activated protein kinase. Plant Cell 2003, 15, 745-759. [CrossRef]

27. Ghawana, S.; Kumar, S.; Ahuja, P.S. Early low-temperature responsive mitogen activated protein kinases RaMPK1 and RaMPK2 from Rheum australe D. Don respond differentially to diverse stresses. Mol. Biol. Rep. 2009, 37, 933. [CrossRef]

28. Danquah, A.; de Zélicourt, A.; Boudsocq, M.; Neubauer, J.; Frei Dit Frey, N.; Leonhardt, N.; Pateyron, S.; Gwinner, F.; Tamby, J.; Ortiz-Masia, D.; et al. Identification and characterization of an ABA-activated MAP kinase cascade in Arabidopsis thaliana. Plant J. 2015, 82, 232-244. [CrossRef]

29. Hahn, A.; Harter, K. Mitogen-activated protein kinase cascades and ethylene: Signaling, biosynthesis, or both? Plant Physiol. 2009, 149, 1207-1210. [CrossRef]

30. Yoo, S.; Cho, Y.; Tena, G.; Xiong, Y.; Sheen, J. Dual control of nuclear EIN3 by bifurcate MAPK cascades in $\mathrm{C}_{2} \mathrm{H}_{4}$ signaling. Nature 2008, 451, 789-795. [CrossRef]

31. Harel-Beja, R.; Sherman, A.; Rubinstein, M.; Eshed, R.; Bar-Ya Akov, I.; Trainin, T.; Ophir, R.; Holland, D. A novel genetic map of pomegranate based on transcript markers enriched with QTLs for fruit quality traits. Tree Genet. Genomes 2015, 11, 109. [CrossRef]

32. Liu, C.; Zhao, Y.; Zhao, X.; Wang, J.; Gu, M.; Yuan, Z. Transcriptomic profiling of pomegranate provides insights into salt tolerance. Agronomy 2020, 10, 44. [CrossRef]

33. Qin, G.; Liu, C.; Li, J.; Qi, Y.; Gao, Z.; Zhang, X.; Yi, X.; Pan, H.; Ming, R.; Xu, Y. Diversity of metabolite accumulation patterns in inner and outer seed coats of pomegranate: Exploring their relationship with genetic mechanisms of seed coat development. Hortic. Res. 2020, 7, 10. [CrossRef] [PubMed]

34. Yan, M.; Zhao, X.; Zhou, J.; Huo, Y.; Ding, Y.; Yuan, Z. The complete chloroplast genomes of Punica granatum and a comparison with other species in lythraceae. Int. J. Mol. Sci. 2019, 20, 2886. [CrossRef]

35. Yuan, Z.; Fang, Y.; Zhang, T.; Fei, Z.; Han, F.; Liu, C.; Liu, M.; Xiao, W.; Zhang, W.; Wu, S.; et al. The pomegranate (Punica granatum L.) genome provides insights into fruit quality and ovule developmental biology. Plant Biotechnol. J. 2018, 16, 1363-1374. [CrossRef]

36. Zhao, X.; Yuan, Z.; Feng, L.; Fang, Y. Cloning and expression of anthocyanin biosynthetic genes in red and white pomegranate. J. Plant Res. 2015, 128, 687-696. [CrossRef]

37. Thomma, B.P.; Penninckx, I.A.; Cammue, B.P.; Broekaert, W.F. The complexity of disease signaling in Arabidopsis. Curr. Opin. Immunol. 2001, 13, 63-68. [CrossRef] 
38. Luo, X.; Li, H.; Wu, Z.; Yao, W.; Zhao, P.; Cao, D.; Yu, H.; Li, K.; Poudel, K.; Zhao, D.; et al. The pomegranate (Punica granatum L.) draft genome dissects genetic divergence between soft- and hard-seeded cultivars. Plant Biotechnol. J. 2019, 18, 955-968. [CrossRef]

39. Kersey, P.J.; Allen, J.E.; Allot, A.; Barba, M.; Boddu, S.; Bolt, B.J.; Carvalho-Silva, D.; Christensen, M.; Davis, P.; Grabmueller, C.; et al. Ensembl Genomes 2018: An integrated omics infrastructure for non-vertebrate species. Nucleic Acids Res. 2017, 46, D802-D808. [CrossRef] [PubMed]

40. Bateman, A.; Birney, E.; Cerruti, L.; Ettwiller, L.; Eddy, S.; Griffiths-Jones, S.; Howe, K.; Marshall, M.; Sonnhammer, E. The pfam protein families database. Nucleic Acids Res. 2002, 30, 276-280. [CrossRef]

41. Finn, R.D.; Clements, J.; Eddy, S.R. HMMER web server: Interactive sequence similarity searching. Nucleic Acids Res. 2011, 39, W29-W37. [CrossRef] [PubMed]

42. Schultz, J.; Milpetz, F.; Bork, P.; Ponting, C.P. SMART, a simple modular architecture research tool: Identification of signaling domains. Proc. Natl. Acad. Sci. USA 1998, 95, 5857-5864. [CrossRef] [PubMed]

43. Marchler-Bauer, A.; Bo, Y.; Han, L.; He, J.; Lanczycki, C.J.; Lu, S.; Chitsaz, F.; Derbyshire, M.K.; Geer, R.C.; Gonzales, N.R.; et al. CDD/SPARCLE: Functional classification of proteins via subfamily domain architectures. Nucleic Acids Res. 2017, 45, D200-D203. [CrossRef]

44. Artimo, P.; Jonnalagedda, M.; Arnold, K.; Baratin, D.; Csardi, G.; de Castro, E.; Duvaud, S.; Flegel, V.; Fortier, A.; Gasteiger, E.; et al. ExPASy: SIB bioinformatics resource portal. Nucleic Acids Res. 2012, 40, W597-W603. [CrossRef] [PubMed]

45. Larkin, M.; Blackshields, G.; Brown, N.; Chenna, R.; Mcgettigan, P.; McWilliam, H.; Valentin, F.; Wallace, I.; Wilm, A.; López, R.; et al. Clustal W and Clustal X version 2.0. Bioinformatics 2007, 23, 2947-2948. [CrossRef]

46. Nicholas, K.B.; Nicholas, H.; Deerfield, D. GeneDoc: Analysis and visualization of genetic variation. Embnew. News 1996, 4, 14.

47. Kumar, S.; Stecher, G.; Tamura, K. MEGA7: Molecular evolutionary genetics analysis version 7.0 for bigger datasets. Mol. Biol. Evol. 2016, 33, 1870-1874. [CrossRef]

48. Bailey, T.L.; Boden, M.; Buske, F.A.; Frith, M.; Grant, C.E.; Clementi, L.; Ren, J.; Li, W.W.; Noble, W.S. MEME SUITE: Tools for motif discovery and searching. Nucleic Acids Res. 2009, 37, W202-W208. [CrossRef] [PubMed]

49. Chen, C.; Xia, R.; Chen, H.; He, Y. TBtools, a toolkit for biologists integrating various HTS-data handling tools with a user-friendly interface. bioRxiv 2018, 289660. [CrossRef]

50. Magali, L.; Patrice, D.; Gert, T.; Kathleen, M.; Yves, M.; Yves, V.D.P.; Pierre, R.; Stephane, R. PlantCARE, a database of plant cis-acting regulatory elements and a portal to tools for in silico analysis of promoter sequences. Nucleic Acids Res. 2002, 30, 325-327.

51. Bray, N.L.; Pimentel, H.; Melsted, P.; Pachter, L. Near-optimal probabilistic RNA-seq quantification. Nat. Biotechnol. 2016, 34, 525-527. [CrossRef] [PubMed]

52. Racine, J.S. RStudio: A platform-independent IDE for R and sweave. J. Appl. Econ. 2012, 27, $167-172$. [CrossRef]

53. Ophir, R.; Sherman, A.; Rubinstein, M.; Eshed, R.; Sharabi-Schwager, M.; Harel Beja, R.; Bar-Ya'Akov, I.; Holland, D. Single-nucleotide polymorphism markers from de-novo assembly of the pomegranate transcriptome reveal germplasm genetic diversity. PLOS ONE 2014, 9, e88998. [CrossRef]

54. Chen, L.; Zhang, J.; Li, H.; Niu, J.; Xue, H.; Liu, B.; Wang, Q.; Luo, X.; Zhang, F.; Zhao, D.; et al. Transcriptomic analysis reveals candidate genes for female sterility in pomegranate flowers. Front. Plant Sci. 2017, 8, 1430. [CrossRef] [PubMed]

55. Ono, N.N.; Britton, M.T.; Fass, J.N.; Nicolet, C.M.; Lin, D.; Tian, L. Exploring the transcriptome landscape of pomegranate fruit peel for natural product biosynthetic gene and SSR marker discovery. Integr. Plant Biol. 2011, 53, 800-813. [CrossRef] [PubMed]

56. Wang, G.; Lovato, A.; Polverari, A.; Wang, M.; Liang, Y.; Ma, Y.; Cheng, Z. Genome-wide identification and analysis of mitogen activated protein kinase kinase kinase gene family in grapevine (Vitis vinifera). BMC Plant Biol. 2014, 14, 219. [CrossRef]

57. Wang, L.; Hu, W.; Tie, W.; Ding, Z.; Ding, X.; Liu, Y.; Yan, Y.; Wu, C.; Peng, M.; Xu, B.; et al. The MAPKKK and MAPKK gene families in banana: Identification, phylogeny and expression during development, ripening and abiotic stress. Sci. Rep. 2017, 7, 1159. [CrossRef] 
58. Zhang, S.; Xu, R.; Luo, X.; Jiang, Z.; Shu, H. Genome-wide identification and expression analysis of MAPK and MAPKK gene family in Malus domestica. Gene 2013, 531, 377-387. [CrossRef]

59. Bohnert, H.; Nelson, D.; Jensen, R. Adaptations to environmental stresses. Plant Cell 1995, 7, $1099-1111$. [CrossRef]

60. Nicole, M.; Hamel, L.; Morency, M.; Beaudoin, N.; Ellis, B.E.; Séguin, A. MAP-ping genomic organization and organ-specific expression profiles of poplar MAP kinases and MAP kinase kinases. BMC Gen. 2006, 7, 223. [CrossRef]

61. Kong, F.; Wang, J.; Cheng, L.; Liu, S.; Wu, J.; Peng, Z.; Lu, G. Genome-wide analysis of the mitogen-activated protein kinase gene family in Solanum lycopersicum. Gene 2012, 499, 108-120. [CrossRef] [PubMed]

62. Wei, C.; Liu, X.; Long, D.; Guo, Q.; Fang, Y.; Bian, C.; Zhang, D.; Zeng, Q.; Xiang, Z.; Zhao, A. Molecular cloning and expression analysis of mulberry MAPK gene family. Plant Physiol. Biochem. 2014, 77, 108-116. [CrossRef]

63. Zhang, S.; Klessig, D.F. MAPK cascades in plant defense signaling. Trends Plant Sci. 2001, 6, 520-527. [CrossRef]

64. Kovtun, Y.; Chiu, W.; Zeng, W.; Sheen, J. Suppression of auxin signal transduction by a MAPK cascade in higher plants. Nature 1998, 395, 716-720. [CrossRef] [PubMed]

65. Liu, Z.; Shi, L.; Liu, Y.; Tang, Q.; Shen, L.; Sheng, Y.; Cai, J.; Yu, H.; Wang, R.; Wen, J.; et al. Genome-wide identification and transcriptional expression analysis of mitogen-activated protein kinase and mitogen-activated protein kinase kinase genes in Capsicum annuum. Front. Plant Sci. 2015, 6. [CrossRef] [PubMed]

66. Wang, J.; Pan, C.; Wang, Y.; Ye, L.; Wu, J.; Chen, L.; Zou, T.; Lu, G. Genome-wide identification of MAPK, MAPKK, and MAPKKK gene families and transcriptional profiling analysis during development and stress response in cucumber. BMC Gen. 2015, 16, 386. [CrossRef]

67. Song, Q.; Li, D.; Dai, Y.; Liu, S.; Huang, L.; Hong, Y.; Zhang, H.; Song, F. Characterization, expression patterns and functional analysis of the MAPK and MAPKK genes in watermelon (Citrullus lanatus). BMC Plant Biol. 2015, 15, 298. [CrossRef]

68. Wang, H.; Gong, M.; Guo, J.; Xin, H.; Gao, Y.; Liu, C.; Dai, D.; Tang, L. Genome-wide identification of Jatropha curcas MAPK, MAPKK, and MAPKKK gene families and their expression profile under cold stress. Sci. Rep. 2018, 8, 16163. [CrossRef]

69. Holub, E. The arms race is ancient history in Arabidopsis, the wildflower. Nat. Rev. 2001, 2, 516-527. [CrossRef]

70. Goyal, R.; Tulpan, D.; Chomistek, N.; González-Peña Fundora, D.; West, C.; Ellis, B.; Frick, M.; Laroche, A.; Foroud, N. Analysis of MAPK and MAPKK gene families in wheat and related Triticeae species. BMC Gen. 2018, 19, 178. [CrossRef]

71. Seyfferth, C.; Tsuda, K. Salicylic acid signal transduction: The initiation of biosynthesis, perception and transcriptional reprogramming. Front. Plant Sci. 2014, 5, 697. [CrossRef]

72. Shariatipour, N.; Heidari, B. Meta-analysis of expression of the stress tolerance associated genes and uncover their cis-regulatory elements in rice (Oryza sativa L.). Open Biol. J. 2020, 13, 39-49. [CrossRef]

73. Itzhaki, H.; Maxson, J.M.; Woodson, W.R. An ethylene-responsive enhancer element is involved in the senescence-related expression of the carnation glutathione-S-transferase (GST1) gene. Proc. Natl. Acad. Sci. USA 1994, 91, 8925-8929. [CrossRef] [PubMed]

74. Gubler, F.; Jacobsen, J. Gibberellin-responsive elements in the promoter of a barley high-pl [alpha]-amylase gene. Plant Cell 1992, 4, 1435-1441. [CrossRef] [PubMed]

75. Guiltinan, M.J.; Marcotte, W.R., Jr.; Quatrano, R.S. A plant leucine zipper protein that recognizes an abscisic acid response element. Science 1990, 250, 267-271. [CrossRef]

76. Goldsbrough, A.P.; Albrecht, H.; Stratford, R. Salicylic acid-inducible binding of a tobacco nuclear protein to a $10 \mathrm{bp}$ sequence which is highly conserved amongst stress-inducible genes. Plant J. 1993, 3, 563-571. [CrossRef]

77. Krysan, P.; Colcombet, J. Cellular complexity in MAPK signaling in plants: Questions and emerging tools to answer them. Front. Plant Sci. 2018, 9. [CrossRef] [PubMed] 
78. Chardin, C.; Schenk, S.; Hirt, H.; Colcombet, J.; Krapp, A. Review: Mitogen-activated protein kinases in nutritional signaling in Arabidopsis. Plant Sci. 2017, 260. [CrossRef]

79. Zhao, F.Y.; Hu, F.; Zhang, S.Y.; Wang, K.; Zhang, C.R.; Liu, T. MAPKs regulate root growth by influencing auxin signaling and cell cycle-related gene expression in cadmium-stressed rice. Environ. Sci. Pollut. Res. 2013, 20, 5449-5460. [CrossRef]

(C) 2020 by the authors. Licensee MDPI, Basel, Switzerland. This article is an open access article distributed under the terms and conditions of the Creative Commons Attribution (CC BY) license (http://creativecommons.org/licenses/by/4.0/). 